\title{
Aa. Vv., "Didon se sacrifiant" d'Étienne Jodelle, sous la direction de Charlotte Bonnet, Anne Boutet, Christine de Buzon et Élise Gauthier
}

\section{Maurizio Busca}

\section{OpenEdition}

\section{Journals}

Edizione digitale

URL: http://journals.openedition.org/studifrancesi/1302

DOI: 10.4000/studifrancesi. 1302

ISSN: 2421-5856

\section{Editore}

Rosenberg \& Sellier

\section{Edizione cartacea}

Data di pubblicazione: 1 décembre 2015

Paginazione: $580-581$

ISSN: 0039-2944

\section{Notizia bibliografica digitale}

Maurizio Busca, "Aa. Vv., "Didon se sacrifiant" d'Étienne Jodelle, sous la direction de Charlotte Bonnet, Anne Boutet, Christine de Buzon et Élise Gauthier», Studi Francesi [Online], 177 (LIX | III) | 2015, online dal 01 décembre 2015, consultato il 13 janvier 2021. URL: http://journals.openedition.org/ studifrancesi/1302 ; DOI: https://doi.org/10.4000/studifrancesi.1302

Questo documento è stato generato automaticamente il 13 janvier 2021.

\section{cc)}

Studi Francesi è distribuita con Licenza Creative Commons Attribuzione - Non commerciale - Non opere derivate 4.0 Internazionale. 


\title{
Aa. Vv., "Didon se sacrifiant" d'Étienne Jodelle, sous la direction de Charlotte Bonnet, Anne Boutet, Christine de Buzon et Élise Gauthier
}

\author{
Maurizio Busca
}

\section{NOTIZIA}

AA. VV., "Didon se sacrifiant" d'Étienne Jodelle, sous la direction de Charlotte BONNET, Anne BOUTET, Christine de BUzon et Élise GAUTHIER, Tours, Presses Universitaires François-

Rabelais, 2015 («Perspectives littéraires»), pp. 202.

1 Il presente volume, che va ad arricchire il nutrito corpus delle pubblicazioni sulla Didon se sacrifiant apparse negli ultimi tre anni, riunisce i contributi dei cinque specialisti che hanno animato la giornata di studi del 19 ottobre 2013 presso il CESR di Tours. Alcuni degli studi raccolti (segnatamente quelli di BURON e POLIzzI) riprendono questioni già affrontate recentemente dai rispettivi autori, proponendo comunque nuovi sviluppi. Ogni contributo è accompagnato da una bibliografia selettiva, mentre alle pp.17-21 è presente un repertorio delle ultime pubblicazioni dedicate alla tragedia di Jodelle che integra le bibliografie curate da Sabine LARDON e Jean-Claude TERNAUX (aggiornate, queste ultime, al 2013-2014).

2 I contributi raccolti sono i seguenti. Emmanuel BURON, Le sacrifice de Didon, Réseau d'allusions et scénario sous-jacent dans "Didon se sacrifiant" d'Étienne Jodelle, pp. 23-47; John NASSICHUK, «Ceste gent tromperesse...»: «foi», «feinte» et éthique de la parole dans "Didon se sacrifiant" pp.49-113; Gilles PoLIzzI, Didon sur la scène de l'envie: propositions dramaturgiques, pp. 115-150; Sylvain GARNIER, Les chœurs chez Jodelle: évolution des fonctions dramatique, lyrique et morale et de leur articulation, pp.151-182; Mathilde LAMY-HOUDRY, Héros épique, héros tragique: la figure d'Énée de Virgile à Jodelle, pp. 183-196. 
BURON si interroga sul tema del sacrificio, che Jodelle introduce nella sua riscrittura del mito assimilando la figura di Didon a quelle di Ercole morente e di Cristo («sacerdos et hostia», così come la regina di Cartagine è "prestresse et victime»). Assimilazione, questa, certamente problematica: in Didon è assente la componente divina che la condurrebbe all'apoteosi, e la sua morte non apre a una prospettiva di salvezza collettiva. Tuttavia, osservando come Jodelle faccia ricorso anche altrove al motivo della resurrezione di Cristo non già nelle sue implicazioni religiose ma quale immagine del trionfo dell'uomo sulla morte (e in particolare dell'immortalità del poeta), l'A. riconosce in Didon un personaggio che incarna la «vengeance de l'homme» (v. 1966) contro l'umiliazione della caduta imposta dagli dei: attraverso il suicidio, Didon diviene «une figure exemplaire de la grandeur foudroyée» (p. 36). Istituendo infine un parallelo con l'Abraham sacrifiant di Bèze, l'A. mostra come l'Énée di Jodelle, negazione del modello virgiliano del pius Aeneas, rappresenti una sorta di versione esecrabile della figura di Abramo. Il contributo di NASSICHUK parte da uno studio del lessico e della retorica dell'amore nell'opera poetica di Jodelle per verificare la presenza dei medesimi tratti caratteristici nell'opera drammatica. Il tema della «foi» e della «constance», già presente nelle poesie e centrale nella Didon (ma pensiamo anche alla sua rilevanza in altre tragedie coeve, come la Médée di La Péruse), solleva interrogativi di natura morale intorno all'uso ambiguo della retorica politica e amorosa, strumento di persuasione e quindi, potenzialmente, di inganno. La trasposizione di genere operata sul canto IV dell'Eneide, peraltro, crea spazi di espressione della dimensione dell'interiorità che permettono a Jodelle di interrogare i silenzi del testo virgiliano, esplorando il motivo dell'incertezza e del sospetto dell'altro. Anche l'articolo di polizzi guarda all'interiorità dei personaggi, muovendo dagli studi psicanalitici di Melanie Klein sull'invidia e la gratitudine per illustrare le declinazioni e gli effetti dell'envie (invidia, ingratitudine, maldicenza) nei protagonisti della tragedia. L'A. individua nel trattamento jodelliano dell'envie il principale motore della pièce, nonché un'occasione di riflessione morale ed esistenziale. GARNIER esamina invece il problema del ruolo del coro nelle tragedie di Jodelle. Nella Cléopâtre abbiamo un coro che nei primi due atti non interviene nell'azione ma porta su di essa il proprio sguardo, mentre negli ultimi tre diviene un vero e proprio personaggio: in questo modo il drammaturgo può dare ampio spazio a tutte le funzioni (drammatica, lirica, morale) prescritte dall'Ars poetica oraziana. Nella Didon invece Jodelle opera una scelta originale, scindendo il coro in due sezioni (passando quindi dall'espressione di una doxa morale a quella di due posizioni opposte e inconciliabili) e prediligendone la funzione drammatica a discapito di quella lirica; l'A. rileva, inoltre, «un appauvrissement drastique du lyrisme [dont l'inspiration] passe d'une logique poétique enthousiaste à une logique de clarté rhétorique» (p. 176). L'ultimo contributo, di LAMY-HOUDRY, indaga invece le implicazioni del passaggio di genere nella definizione dei personaggi di Énée e Didon. «De l'intertexte épique à l'amplification tragique, l'héroïsme devient problématique» (p. 188); tuttavia, secondo l'A., l'Énée di Jodelle, personaggio epico posto in una situazione tragica, rimane un modello etico positivo che si oppone a Didon, personaggio epico che diviene tragico soccombendo alla passione (in ciò l'A. si distanzia dalla lettura proposta da BURON). 